\title{
The analysis of the operational process of a complex fire alarm system used in transport facilities
}

\author{
Jacek Paś', Tomasz Klimczak², Adam Rosiński ${ }^{3}(\varangle)$, Marek Stawowy ${ }^{3}$ \\ 1. Military University of Technology Faculty of Electronic, Institute of Electronic Systems, Division of Electronic Systems Exploitations, ul. \\ gen. S. Kaliskiego 2, 00-908 Warsaw, Poland \\ 2. The Main School of Fire Service, ul. Juliusza Słowackiego 52/54, 01-629 Warsaw, Poland \\ 3. Warsaw University of Technology, Faculty of Transport, Department of Telecommunications in Transport, ul. Koszykowa 75, 00-662 \\ Warsaw, Poland
}

\begin{abstract}
A fire alarm system (FAS) is a system comprising signalling-alarm devices, which automatically detect and transmit information about fire, but also receivers of fire alarms and receivers for damage signals. Fire alarm systems function in different environmental conditions. During operation they should be in state of fitness. This is determined by the reliability of the assembled units and rational management of the operation process. Therefore a reliability and operational analysis of fire alarm systems as a whole is essential. This article presents an authorial model and an operational and reliability analysis of FAS, which is exploited in a transport building. It also demonstrates relationships occurring in the analysed system, where to an addressable fire alarm central unit with detection loops and control-monitoring loops alarm device lines (with monitored relay outputs for actuation of alarm-signalling devices) were connected. Research and analysis of results for representative FAS, which were exploited in similar environmental conditions, were conducted in order to determine operational and reliability parameters of the investigated system. FAS computer simulation was run during the time $t=1$ year of safety system operation. This led to the calculation of the probability value of the analysed FAS staying in the examined operational states.
\end{abstract}

\author{
Keywords \\ modelling; \\ reliability; \\ operation; \\ fire alarm systems (FAS), \\ simulation
}

\section{Article History \\ Received: 28 December 2020 \\ Revised: 18 February 2021 \\ Accepted: 03 March 2021}

(C) The Author(s) 2021

\section{Introduction}

The safety of transport facilities is as important as transport safety (Losurdo et al. 2017; Stawowy and Siergiejczyk 2017; Klimczak and Paś 2020). Transport facilities are widely equipped with safety installations, especially with fire alarm systems (FAS), acoustic warning systems (AWS), smoke ventilation systems and fixed extinguishing devices both water and gas based (Ge et al. 2017; Østrem and Sommer 2021). These mentioned systems control signal boxes, distribution boards, teletechnical containers on level crossings, railway stations and railway platforms. In the age of technological advance in transport facilities each investment project is designed jointly with modern fire safety installations (Sharma et al. 2020). Mainly these are fire alarm systems integrated with several technical installations and other fire installations, moreover integrated with building management systems (BMS), video surveillance, intrusion detection system (IDS) and safety systems (Kierzkowski and Kisiel 2015, 2017; Paś et al. 2018). According to the Ministry of the Interior and Administration of Poland (2010), by technical fire safety measures one should understand devices, equipment, systems and construction solutions designed to prevent the formation and spread of fires. The regulation understands fire safety equipment as devices (fixed or semi-fixed, activated manually or automatically) aimed at preventing the formation of, detecting and fighting a fire or limiting its results.

On the basis of the definition in the regulation (Ministry of the Interior and Administration of Poland 2010) Fire Alarm System (FAS) is a system comprising signalling-alarm devices intended for automatic detection and transmittance

E-mail: adro@wt.pw.edu.pl 
of fire information, as well as receivers of fire alarms and receivers of damage signals (Klimczak and Paś 2019) Figure 1.

Having carried out the analysis of fire alarm systems it can be said, that they function in varied environmental conditions (Paś 2016; Krzykowski et al. 2019; Long et al. 2021). During operation they should stay in full fitness (Naziris et al. 2016). This can be affected by the reliability of the constituting components (Forell et al. 2016; Verma et al. 2017), but also the rational management of the operational process (Paś and Klimczak 2019).

Fire alarm systems must meet several requirements, listed both in standards and in guidelines included in regulations (especially in critical infrastructure facilities). One of the most important requirements is: low power consumption (Billinton and Allan 1996; Krzykowski et al. 2019; Rosiński et al. 2019), functionality (Siergiejczyk and Krzykowska 2014), reliability (Laskowski et al. 2015; Mao et al. 2019; Jafari et al. 2020), vibration resistance (Burdzik et al. 2013; Kostrzewski 2018; Kukulski et al. 2019;), information quality (Stawowy et al. 2017) from sensors (Łabowski and Kaniewski 2015; Kaniewski et al. 2019), electromagnetic distortion resistance (Siergiejczyk et al. 2015; Urbancokova et al. 2015; Siergiejczyk et al. 2017; Paś et al. 2020) and subsystem inspection (Duer et al. 2013). One of the effects of complying with the requirements is the introduction of more and more technologically sophisticated FAS (Cadena et al. 2020). That is why conducting reliability and operational analysis of FAS as a whole is so essential. The authors' considerations in this matter are presented in this paper.

\section{Reliability of fire alarm systems}

The issue of hazard detection of fire alarm systems has been the subject matter of scientific papers in recent years. The publication (Mahdipour and Dadkhah 2014) includes a truly interesting study. It presents the development of research of automatic fire detection using intelligent techniques in the first decade of the $21^{\text {st }}$ century. It was conducted factoring in the following four categories: fire detectors, false alarms reduction systems, fire data analysis and fire predictors. Among numerous reviews of many studies, there are researches incorporating FAS reliability. The authors of this paper show what an essential case it is, especially nowadays when dispersed fire alarm systems are applied.

Detailed insights into the development of fire detection by implementing Chemical Sensor Systems are presented by Fonollosa et al. (2018). The authors described in great detail the origination of individual types of solutions aimed at detecting toxic gases generated during a fire. In doing so, they also took into account data processing algorithms. It can be concluded that currently it is appropriate to use multidimensional models to correlate data from multiple sensors.

The publication (Ding et al. 2014) includes speculations over the multisensor information analysis and synthesis. For that purpose the Demspter-Shafer theory was applied which enables assessment of the alarm state of the detector, which contains several independent sensors (flame, smoke, temperature, gas, humidity). With such an approach the likelihood of false alarms is minimised. Consequently it has a positive influence on the operation of fire alarm systems.

Another approach to fire detection was presented in study (Gunawaardena et al. 2016). The authors claim that the probability of fire detection depends mainly on detector distribution. For this reason they suggested an innovative method of detecting fire by processing video image sequence. This helps increase the efficacy of flame detection. The proposed sequence analysis algorithm of frames received from the video surveillance, made it possible (Wu et al. 2019; Mi et al. 2020 ).

A similar approach to fire hazard detection is presented in article (Vijayalakshmi and Muruganand 2017). It proposed camera images analysis algorithm, which uses fuzzy c-means (FCM) method. Due to this a quite high percentage of smoke detection is obtained. The same solution is advantageous for the protection of huge open spaces (Xie and Peng 2019).

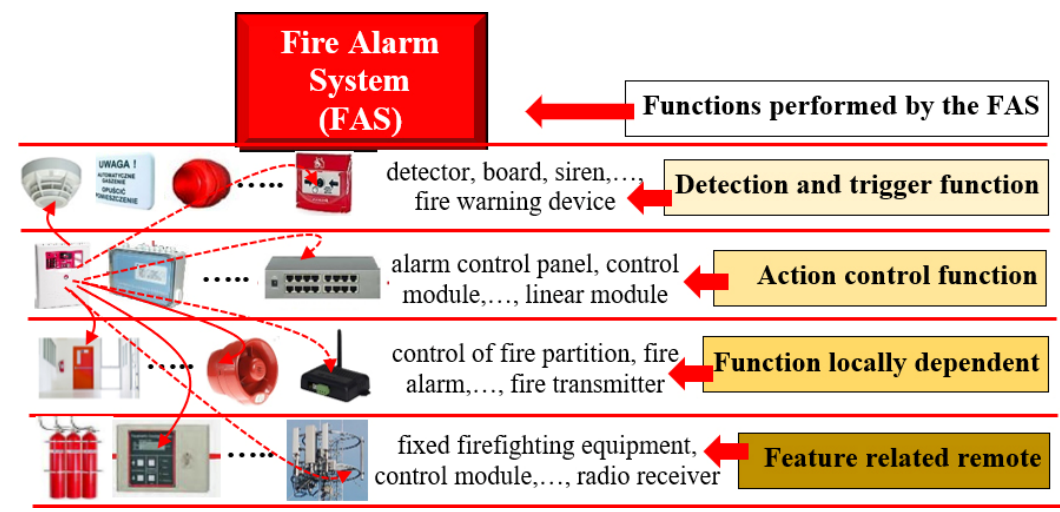

Fig. 1 Basic tasks executed by a fire alarm system [own elaboration] 
A different approach from the abovementioned in reliability-operational analysis of fire alarm systems was employed by Lin (2013). These studies treat FAS as a whole and determine the influence of its configuration on the efficacy of evacuation of people from a high-rise building. Yet the description lacks depth, therefore it is inadequate to determine the influence of FAS reliability structures on the safety of people.

The issue of FAS testing and evaluation of its compliance with standards and regulations is presented by Feo-Arenis et al. (2014). Wireless FAS was characterised and next modelled. The aim of this study was the evaluation of the compliance with EN-54 standard. During the verification of the model an anomaly of FAS functionality was detected. A similar approach was chosen by the authors of this article, yet within the aspect of reliability-operational analysis.

Interesting scholar studies in the field of reliability and operation of fire alarm systems are presented in a chapter of a monograph (Joglar 2016). Basic theoretical issues about reliability and operational systems are described. Attention is drawn to the operational process of repairable and unrepairable facilities. The models presented in this scientific work are very simple and of no use in the analysis of dispersed fire alarm systems. That is why the speculations in this paper are crucial.

Issues of analysis of big fire alarm systems are presented by Jee et al. (2014). The functioning of conventional fire alarm systems was analysed and followed by a presentation of solutions which enable the usage of conventional detectors in constructing FAS with the possibility of tracking the seat of the fire. Yet this work does not contain a comparison of these two solutions in terms of reliability and operation.

An important group of publications on fire alarm systems is the one that analyses FAS in the context of process safety and risk engineering. An example of that can be the publication (Jennings 2020) in which the author examines the impact of servicing in the offshore oil and gas industry on crisis situations. Security managers receive information from e.g. FAS and respond to alarms in accordance with appropriate procedures. This should prevent disasters.

Idris et al. (2020) also study the impact of the human factor on the reliability of fire alarm systems. Two types of alarms and three types of detectors were taken into account: flammable gas detectors, flame detectors, and toxic gas detectors. As a result of the conducted research, it was established that the human factor is a critical element in ensuring the effective operation of FAS.

Numerous publications consider fire alarm systems in the context of fire risk analysis. Then FAS can significantly minimize the loss caused by a fire, which is important both in transport and industrial facilities. Such findings are included by Ding et al. (2020). The authors described the issues of fire risk assessment during cotton storage. Models were created (using Bow-tie, Fault tree, Bayesian network) to determine the relationship between fire events, FAS and fire consequences. The conducted analysis allowed to conclude that the detection and extinguishing of the fire is most significant in the prevention of large fires.

Risk analysis is not only applicable directly to fire alarm systems, but is also relevant in a broad view of fire phenomena. This was presented by Wang et al. (2018). The authors, using the Bayesian theory, developed an evaluation model in the event of a fire in the subway. They took into account both psychological and behavioural reactions of the evacuees. The performed analysis led to a conclusion that further improvement is recommended in order to avoid fatalities.

Despite so many advanced analyses in the field of fire alarm systems, there is a lack of studies dealing with the issues of reliability-operational analysis of these systems as a whole. Such studies have been undertaken by authors in the following sections of this article. These should be acknowledged as an innovative approach in the analysis of FAS.

\section{Focused FAS with addressable detection loops, fire protection devices control loop and alarm devices lines}

Figure 2 presents a focused fire alarm system based on an addressable fire alarm central unit with detection loops with detectors and manual fire alarms, control loop and alarm devices lines. Such a system supervises railway station facility with two platforms. Detection loops are divided in such a way that the first one supervises the railway station with a separate room, in which fire alarm central unit is located. The second and third loop supervises respectively the first and second platform. The forth loop is the control and monitoring loop, which controls and monitors fire protection and technical devices in the area of the railway station and in the area of all platforms (Klimczak and Paś 2020). The control of fire protection devices has been programmed in accordance with an accepted fire scenario of fire alarm and technical systems operation in case of fire.

Due to the application of the detection lines and loops there are restrictions connected to the number of detectors and manual call points (MPCs) in FAS. Existing regulations and standards impose the following restrictions: open detection lines - type B radiation - maximally 32 detectors or 10 MPCs, type A dual power supply loop line detectors maximally 128-line elements (e.g. detectors and MPCs). Loop lines can be accompanied with side lines connected to an adapter with a maximum number of line elements like in open lines, yet the number of elements on the side lines is added to the overall number of elements on the detection 


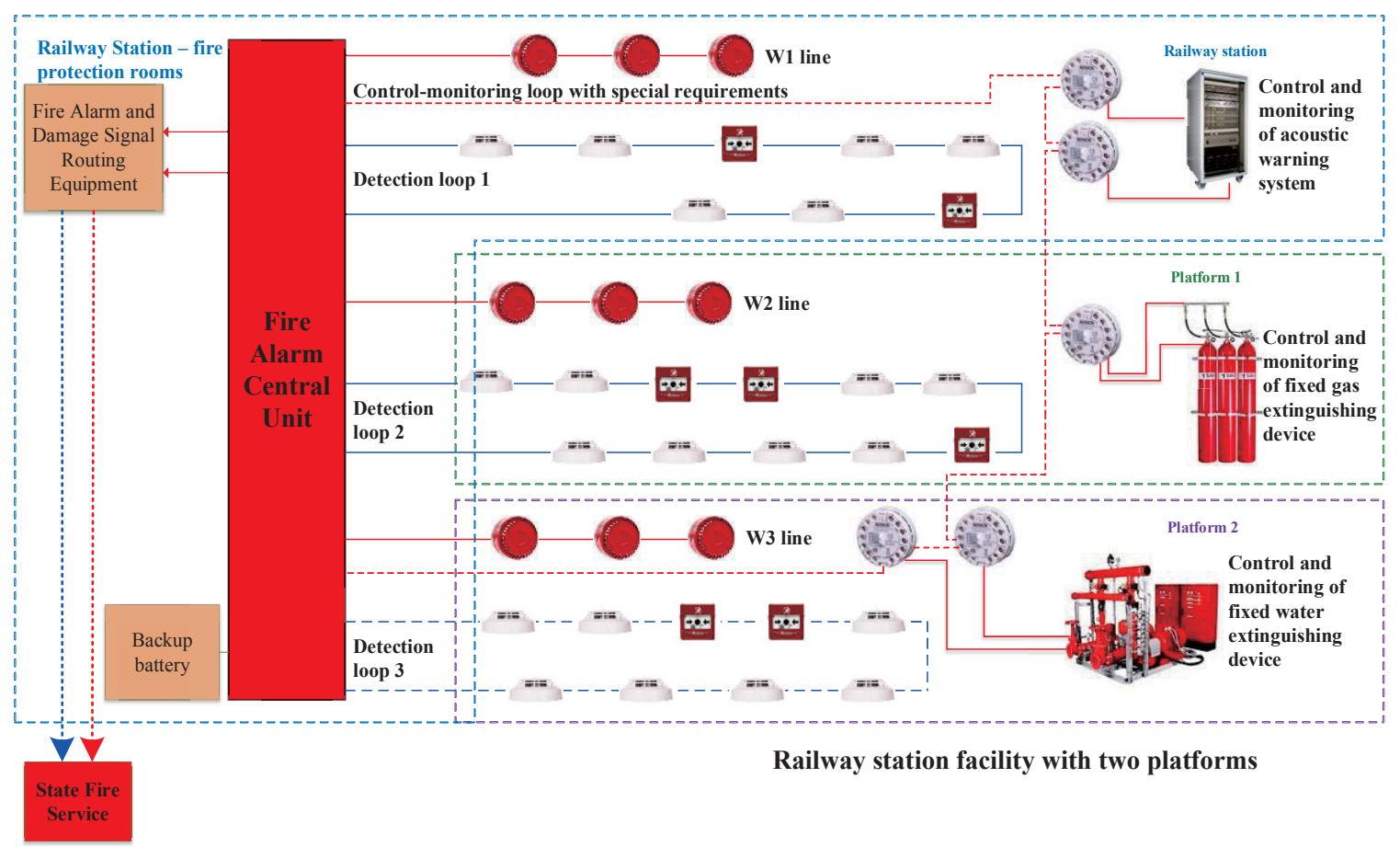

Fig. 2 Focused fire alarm system with addressable fire alarm central unit with detection and control-monitoring loops, alarm devices lines (with monitored relay outputs for actuation of alarm-signalling devices), where lines W1, W2, W3 constitute separate acoustic signalling devices respectively on the surface of the railway station, platform 1 and platform 2 [own elaboration]

loop. In side lines, for example, several detectors can supervise a single room and then the connection with an adapter results in the detectors having a mutual address. The restriction of the maximum number of line elements on the line or loop derive also from the acceptable in the regulation maximum detection area to $1600 \mathrm{~m}^{2}$ and a maximum area of $6000 \mathrm{~m}^{2}$ for several fire zones, which can be protected by one detection loop.

The complex fire alarm system shown in Figure 2 monitors the condition of the fixed HFC-227ea gas extinguishing device (proprietary trade name FM-200 ${ }^{\circledR}$ ). The fixed gas extinguisher is a system subordinate to FAS and most often it is an active fire protection (strategic due to process safety) of rooms in the monitored building. HFC-227ea (1,1,1,2,3,3,3-heptafluoropropane, $\left.\mathrm{CF}_{3} \mathrm{CHFCF}_{3}\right)$ is an active extinguishing agent. It extinguishes flames very quickly by a combination of physical and chemical mechanisms. The physical mechanism of flame suppression is mainly based on the agent's ability to absorb heat, which lowers the flame temperature and slows down the radical chain reaction occurring in the flame. HFC-227ea also acts chemically by breaking the chain reaction responsible for the spread of fire. The extinguishing agent HFC-227ea is a heptafluoropropane, which is a hydrofluorocarbon and has the symbol $\mathrm{CF}_{3} \mathrm{CHFCF}_{3}$.

A room protected by fixed gas extinguishing devices must be a separate fire zone. Due to the storage of flammable liquids, additional safety measures are recommended, such as trays protecting against the spread of flammable liquid as well as against possible contamination of the environment.

A fixed extinguishing device, colloquially known also as a gas extinguishing system, includes tanks with the extinguishing agent, appropriately attached to the walls or the structure of the building. These tanks are connected with fire extinguishing pipes fitted to the walls and ceilings with suitable and durable slings. The pipes are equipped at the ends with specially selected ejection nozzles. These are arranged so as to evenly distribute the extinguishing gas and to ensure the ejection of the extinguishing agent in the calculated time, to obtain the extinguishing concentration in the extinguished area. The fixed extinguishing device also consists of an electric control device, based in particular on a dedicated extinguishing control panel, start and pause buttons, detectors and signaling devices. The most important functions performed by the fixed extinguishing device include: early detection of a fire phenomenon through fire detectors or suction systems, automatic start-up of the fire extinguishing device through the use of e.g. linear coincidence, manual activation of the fire extinguishing device via the START Extinguishing buttons, activation of a warning signal for personnel to ensure safe evacuation, giving a gas release signal to the electromagnetic trigger of the valve of the extinguishing gas tank and activating the devices sealing the extinguishing zone and relieving the pressure of the 
extinguishing zone. To activate automatically the fire extinguishing device, it is most common to apply a coincidence (interdependence) of signals from two groups of detectors - called a two-zone coincidence, a two-detector coincidence (two detectors on two independent detection lines) or a two-line coincidence. Coincidence is one of the most effective ways to eliminate false alarms.

UV/IR multispectral flame detectors are used to detect typical alcohol, n-heptane, gasoline, aviation fuel and hydrocarbon fires. The latest neural network technology allows to distinguish between real flames and sources of false fire alarms, but also to detect flame from a distance. The employment of appropriate technical solutions - a separate fire zone, protection trays, multispectral UV/IR flame detectors - in conjunction with the processing of alarm signals using neural networks reduces the risk of fire spreading and material losses that may occur in the protected facility. The use of modern detectors for detecting the characteristics of a fire also reduces the risk of a false alarm in the facility.

Short-circuit isolators (SCIs) in the case of FAS are crucial in protecting loop devices against short-circuit and overload. In the event of a short circuit in loop detection lines, the use of such solutions (SCI) prevents inability and immobilization of many line devices. SCIs are grouped into autonomous and CSP-controlled, and their operation depends on changes in voltage $(U)$ or current $(I)$, which indirectly determines the value of resistance $R$ in a given detection loop. Figure 3 shows the SCI model reacting to changes in the voltage value in the detection line caused by the change of resistance.

A graph of operational process of a focused fire alarm system is presented in Figure 4.

The system presented in Figure 4 can be described with the following Kolmogorov-Chapman Eqs. (1):

$$
\begin{aligned}
R_{0}^{\prime}(t)= & -\lambda_{\mathrm{CSP}} \cdot R_{0}(t)-\lambda_{\mathrm{W} 1} \cdot R_{0}(t)-\lambda_{\mathrm{W} 2} \cdot R_{0}(t)-\lambda_{\mathrm{W} 3} \cdot R_{0}(t) \\
& -\lambda_{1} \cdot R_{0}(t)-\lambda_{\mathrm{M} 1} \cdot R_{0}(t)+\mu_{\mathrm{CSP}} \cdot Q_{\mathrm{B}}(t)+\mu_{\mathrm{W} 1} \cdot Q_{\mathrm{ZW} 1}(t) \\
& +\mu_{\mathrm{W} 2} \cdot Q_{\mathrm{ZW} 2}(t)+\mu_{\mathrm{W} 3} \cdot Q_{\mathrm{ZW} 3}(t)+\mu_{1} \cdot Q_{\mathrm{ZC} 1}(t) \\
& +\mu_{\mathrm{M} 1} \cdot Q_{\mathrm{ZM} 1}(t)
\end{aligned}
$$

$$
\begin{aligned}
& Q_{\mathrm{ZW} 1}^{\prime}(t)=-\mu_{\mathrm{W} 1} \cdot Q_{\mathrm{ZW} 1}(t)-\lambda_{\mathrm{W} 11} \cdot Q_{\mathrm{ZW} 1}(t)-\lambda_{\mathrm{L} 1} \cdot Q_{\mathrm{ZW} 1}(t) \\
& +\mu_{\mathrm{W} 11} \cdot Q_{\mathrm{B}}(t)+\lambda_{\mathrm{W} 1} \cdot R_{0}(t)+\mu_{\mathrm{L} 1} \cdot Q_{\mathrm{ZW} 2}(t) \\
& Q_{\mathrm{ZW} 2}^{\prime}(t)=-\mu_{\mathrm{W} 2} \cdot Q_{\mathrm{ZW} 2}(t)-\lambda_{\mathrm{W} 22} \cdot Q_{\mathrm{ZW} 2}(t)-\mu_{\mathrm{L} 1} \cdot Q_{\mathrm{ZW} 2}(t) \\
& -\lambda_{\mathrm{L} 2} \cdot Q_{\mathrm{ZW} 2}(t)+\mu_{\mathrm{W} 22} \cdot Q_{\mathrm{B}}(t)+\lambda_{\mathrm{W} 2} \cdot R_{0}(t) \\
& +\mu_{\mathrm{L} 2} \cdot Q_{\mathrm{ZW} 3}(t)+\lambda_{\mathrm{L} 1} \cdot Q_{\mathrm{ZW} 1}(t) \\
& Q_{\mathrm{ZW} 3}^{\prime}(t)=-\mu_{\mathrm{W} 3} \cdot Q_{\mathrm{ZW} 3}(t)-\lambda_{\mathrm{W} 33} \cdot Q_{\mathrm{ZW} 3}(t)-\mu_{\mathrm{L} 2} \cdot Q_{\mathrm{ZW} 3}(t) \\
& +\mu_{\mathrm{W} 33} \cdot Q_{\mathrm{B}}(t)+\lambda_{\mathrm{W} 3} \cdot R_{0}(t)+\lambda_{\mathrm{L} 2} \cdot Q_{\mathrm{ZW} 2}(t) \\
& Q_{\mathrm{ZC} 1}^{\prime}(t)=-\mu_{1} \cdot Q_{\mathrm{ZC} 1}(t)-\lambda_{2} \cdot Q_{\mathrm{ZC} 1}(t)+\mu_{2} \cdot Q_{\mathrm{ZC} 2}(t)+\lambda_{1} \cdot R_{0}(t) \\
& Q_{\mathrm{ZC} 2}^{\prime}(t)=-\mu_{2} \cdot Q_{\mathrm{ZC} 2}(t)-\lambda_{3 \mathrm{R}} \cdot Q_{\mathrm{ZC} 2}(t)+\mu_{3 \mathrm{R}} \cdot Q_{\mathrm{ZR} 1}(t) \\
& +\lambda_{2} \cdot Q_{\mathrm{ZC} 1}(t) \\
& Q_{\mathrm{ZR} 1}^{\prime}(t)=-\mu_{3 \mathrm{R}} \cdot Q_{\mathrm{ZR} 1}(t)-\lambda_{3} \cdot Q_{\mathrm{ZR} 1}(t)+\mu_{3} \cdot Q_{\mathrm{ZC} 3}(t) \\
& +\lambda_{3 \mathrm{R}} \cdot Q_{\mathrm{ZC} 2}(t) \\
& Q_{\mathrm{ZC} 3}^{\prime}(t)=-\mu_{3} \cdot Q_{\mathrm{ZC} 3}(t)-\lambda_{4} \cdot Q_{\mathrm{ZC} 3}(t)+\mu_{4} \cdot Q_{\mathrm{ZC} 4}(t) \\
& +\lambda_{3} \cdot Q_{\mathrm{ZR} 1}(t) \\
& Q_{\mathrm{ZC} 4}^{\prime}(t)=-\mu_{4} \cdot Q_{\mathrm{ZC} 4}(t)-\lambda_{5 \mathrm{R}} \cdot Q_{\mathrm{ZC} 4}(t)+\mu_{5 \mathrm{R}} \cdot Q_{\mathrm{ZR} 2}(t) \\
& +\lambda_{4} \cdot Q_{\mathrm{ZC} 3}(t) \\
& Q_{\mathrm{ZR} 2}^{\prime}(t)=-\mu_{5 \mathrm{R}} \cdot Q_{\mathrm{ZR} 2}(t)-\lambda_{6} \cdot Q_{\mathrm{ZR} 2}(t)+\mu_{6} \cdot Q_{\mathrm{ZC} 5}(t) \\
& +\lambda_{5 \mathrm{R}} \cdot Q_{\mathrm{ZC} 4}(t) \\
& Q_{\mathrm{ZC} 5}^{\prime}(t)=-\mu_{6} \cdot Q_{\mathrm{ZC} 5}(t)-\lambda_{7} \cdot Q_{\mathrm{ZC} 5}(t)+\mu_{7} \cdot Q_{\mathrm{ZC} 6}(t) \\
& +\lambda_{6} \cdot Q_{\mathrm{ZR} 2}(t) \\
& Q_{\mathrm{ZC} 6}^{\prime}(t)=-\mu_{7} \cdot Q_{\mathrm{ZC} 6}(t)-\lambda_{8} \cdot Q_{\mathrm{ZC} 6}(t)+\mu_{8} \cdot Q_{\mathrm{B}}(t)+\lambda_{7} \cdot Q_{\mathrm{ZC} 5}(t) \\
& Q_{\mathrm{ZM} 1}^{\prime}(t)=-\mu_{\mathrm{M} 1} \cdot Q_{\mathrm{ZM} 1}(t)-\lambda_{\mathrm{M} 2} \cdot Q_{\mathrm{ZM} 1}(t)+\mu_{\mathrm{M} 2} \cdot Q_{\mathrm{ZK} 1}(t) \\
& +\lambda_{\mathrm{M} 1} \cdot R_{0}(t) \\
& Q_{\mathrm{ZK} 1}^{\prime}(t)=-\mu_{\mathrm{M} 2} \cdot Q_{\mathrm{ZK} 1}(t)-\lambda_{\mathrm{M} 3} \cdot Q_{\mathrm{ZK} 1}(t)+\mu_{\mathrm{M} 3} \cdot Q_{\mathrm{ZM} 2}(t) \\
& +\lambda_{\mathrm{M} 2} \cdot Q_{\mathrm{ZM} 1}(t) \\
& Q_{\mathrm{ZM} 2}^{\prime}(t)=-\mu_{\mathrm{M} 3} \cdot Q_{\mathrm{ZM} 2}(t)-\lambda_{\mathrm{M} 4} \cdot Q_{\mathrm{ZM} 2}(t)+\mu_{\mathrm{M} 4} \cdot Q_{\mathrm{ZM} 3}(t) \\
& +\lambda_{\mathrm{M} 3} \cdot Q_{\mathrm{ZK} 1}(t) \\
& Q_{\mathrm{ZM} 3}^{\prime}(t)=-\mu_{\mathrm{M} 4} \cdot Q_{\mathrm{ZM} 3}(t)-\lambda_{\mathrm{M} 5} \cdot Q_{\mathrm{ZM} 3}(t)+\mu_{\mathrm{M} 5} \cdot Q_{\mathrm{ZM} 4}(t) \\
& +\lambda_{\mathrm{M} 4} \cdot Q_{\mathrm{ZM} 2}(t) \\
& Q_{\mathrm{ZM} 4}^{\prime}(t)=-\mu_{\mathrm{M} 5} \cdot Q_{\mathrm{ZM} 4}(t)-\lambda_{\mathrm{M} 6} \cdot Q_{\mathrm{ZM} 4}(t)+\mu_{\mathrm{M} 6} \cdot Q_{\mathrm{ZK} 2}(t) \\
& +\lambda_{\mathrm{M} 5} \cdot Q_{\mathrm{ZM} 3}(t) \\
& Q_{\mathrm{ZK} 2}^{\prime}(t)=-\mu_{\mathrm{M} 6} \cdot Q_{\mathrm{ZK} 2}(t)-\lambda_{\mathrm{M} 7} \cdot Q_{\mathrm{ZK} 2}(t)+\mu_{\mathrm{M} 7} \cdot Q_{\mathrm{ZM} 5}(t) \\
& +\lambda_{\mathrm{M} 6} \cdot \mathrm{Q}_{\mathrm{ZM} 4}(t)
\end{aligned}
$$

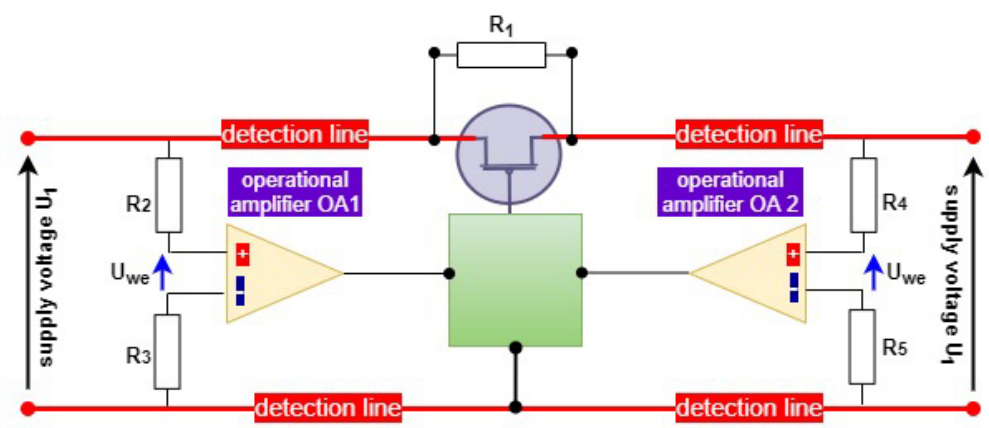

Fig. 3 SCI model in detection loops [own elaboration] 


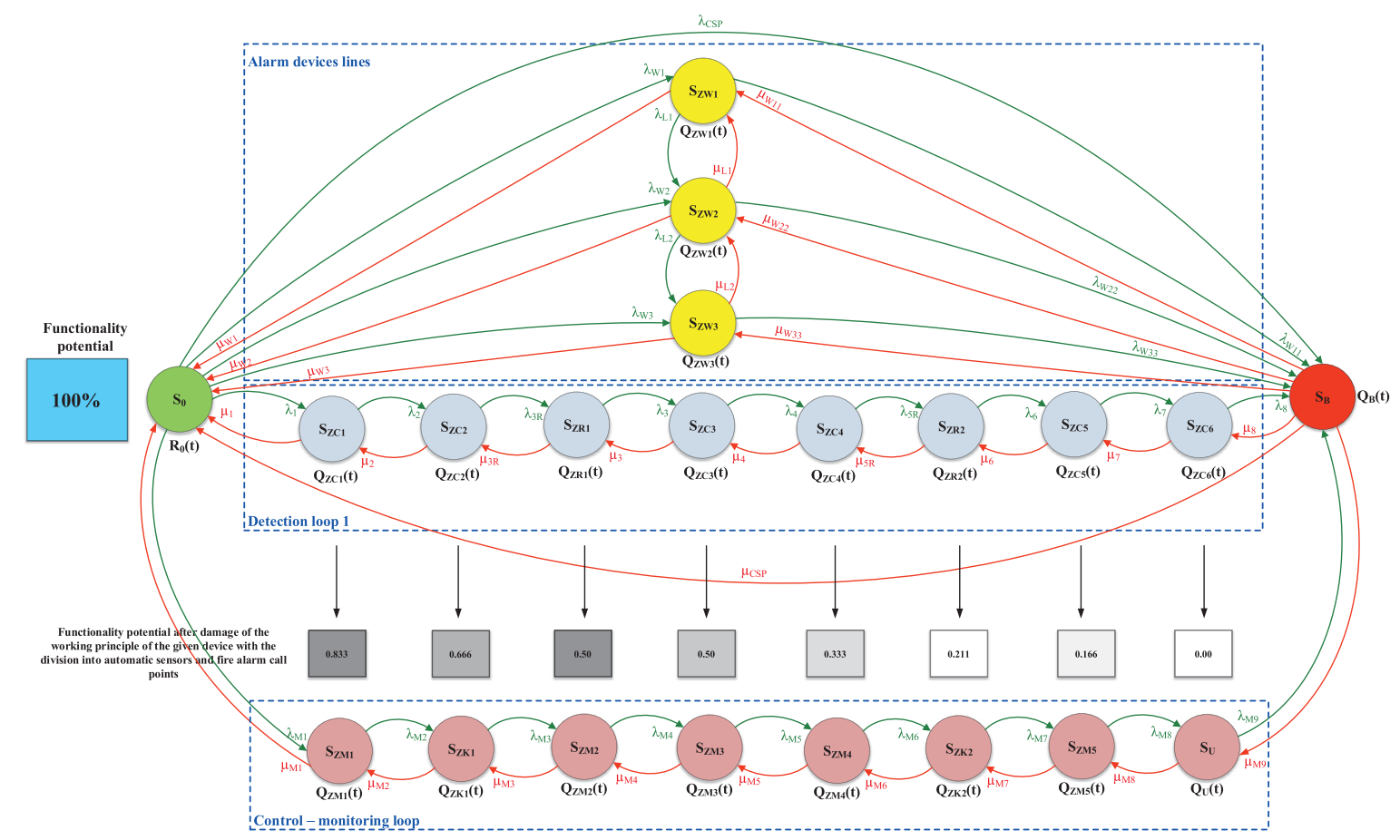

Fig. 4 Relationships occurring in a focused fire alarm system with an addressable fire alarm central unit with detection and controlmonitoring loops, alarm devices lines (with monitored relay outputs for actuation of alarm-signalling devices) [own elaboration] where $R_{0}(t)$ - probability function of the system staying in the state of full fitness $\mathrm{S}_{0}$;

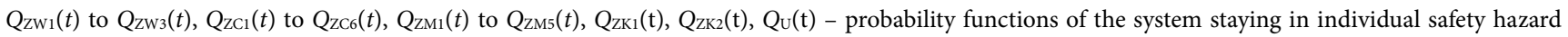
states;

$Q_{B}(t)$ - probability function of the system staying in the state of safety unreliability $S_{B} ;$

$\lambda_{\mathrm{CSP}}$ - intensity of transition from the state of full fitness $\mathrm{S}_{0}$ to the state of safety unreliability $\mathrm{S}_{\mathrm{B}}$;

$\mu_{\mathrm{CSP}}$ - intensity of transition from the state of safety unreliability $\mathrm{S}_{\mathrm{B}}$ to the state of full fitness $\mathrm{S}_{0}$;

$\lambda_{1}, \lambda_{2}, \lambda_{3}, \ldots$ - intensity of transitions from the state of full fitness $S_{0}$ or the state of safety hazard to the state of safety unreliability $S_{B}-$ according to the designations as in Fig. 4;

$\mu_{1}, \mu_{2}, \mu_{3}, \ldots$ - intensity transitions from the state of safety unreliability $S_{B}$ to the state of safety hazard or state of full fitness $S_{0}-$ according to the designations as in Fig. 4 .

$$
\begin{aligned}
Q_{\mathrm{ZM} 5}^{\prime}(t)= & -\mu_{\mathrm{M} 7} \cdot Q_{\mathrm{ZM} 5}(t)-\lambda_{\mathrm{M} 8} \cdot Q_{\mathrm{ZM} 5}(t)+\mu_{\mathrm{M} 8} \cdot Q_{\mathrm{U}}(t) \\
& +\lambda_{\mathrm{M} 7} \cdot Q_{\mathrm{ZK} 2}(t) \\
Q_{\mathrm{U}}^{\prime}(t)= & -\mu_{\mathrm{M} 8} \cdot Q_{\mathrm{U}}(t)-\lambda_{\mathrm{M} 9} \cdot Q_{\mathrm{U}}(t)+\mu_{\mathrm{M} 9} \cdot Q_{\mathrm{B}}(t)+\lambda_{\mathrm{M} 8} \cdot Q_{\mathrm{ZM} 5}(t) \\
Q_{\mathrm{B}}^{\prime}(t)= & -\mu_{\mathrm{W} 11} \cdot Q_{\mathrm{B}}(t)-\mu_{\mathrm{W} 22} \cdot Q_{\mathrm{B}}(t)-\mu_{\mathrm{W} 33} \cdot Q_{\mathrm{B}}(t) \\
& -\mu_{8} \cdot Q_{\mathrm{B}}(t)-\mu_{\mathrm{CSP}} \cdot Q_{\mathrm{B}}(t)-\mu_{\mathrm{M} 9} \cdot Q_{\mathrm{B}}(t)+\lambda_{\mathrm{CSP}} \cdot R_{0}(t) \\
& +\lambda_{\mathrm{W} 11} \cdot Q_{\mathrm{ZW} 1}(t)+\lambda_{\mathrm{W} 22} \cdot Q_{\mathrm{ZW} 2}(t)+\lambda_{\mathrm{W} 33} \cdot Q_{\mathrm{ZW} 3}(t) \\
& +\lambda_{8} \cdot Q_{\mathrm{ZC} 6}(t)+\lambda_{\mathrm{M} 9} \cdot Q_{\mathrm{U}}(t)
\end{aligned}
$$

Adopting the baselines conditions (2):

$$
\begin{aligned}
& R_{0}(t)=1 \\
& Q_{\mathrm{ZW} 1}(0)=Q_{\mathrm{ZW} 2}(0)=Q_{\mathrm{ZW} 3}(0)=Q_{\mathrm{ZC} 1}(0)=Q_{\mathrm{ZC} 2}(0)= \\
& Q_{\mathrm{ZR} 1}(0)=Q_{\mathrm{ZC} 3}(0)=Q_{\mathrm{ZC} 4}(0)=Q_{\mathrm{ZR} 2}(0)=Q_{\mathrm{ZC} 5}(0)= \\
& Q_{\mathrm{ZC} 6}(0)=Q_{\mathrm{ZM} 1}(0)=Q_{\mathrm{ZK} 1}(0)=Q_{\mathrm{ZM} 2}(0)=Q_{\mathrm{ZM} 3}(0)= \\
& Q_{\mathrm{ZM} 4}(0)=Q_{\mathrm{ZK} 2}(0)=Q_{\mathrm{ZM} 5}(0)=Q_{\mathrm{U}}(0)=Q_{\mathrm{B}}(0)=0
\end{aligned}
$$

and employing the Laplace transform the following system of linear equations is achieved:

$$
\begin{aligned}
& \left(s+\lambda_{\mathrm{CSP}}+\lambda_{\mathrm{W} 1}+\lambda_{\mathrm{W} 2}+\lambda_{\mathrm{W} 3}+\lambda_{1}+\lambda_{\mathrm{M} 1}\right) \cdot R_{0}{ }^{*}(s)-\mu_{\mathrm{CSP}} \cdot Q_{\mathrm{B}}{ }^{*}(s) \\
& \quad-\mu_{\mathrm{W} 1} \cdot Q_{\mathrm{ZW} 1}{ }^{*}(s)-\mu_{\mathrm{W} 2} \cdot Q_{\mathrm{ZW} 2}{ }^{*}(s)-\mu_{\mathrm{W} 3} \cdot Q_{\mathrm{ZW} 3}{ }^{*}(s) \\
& \quad-\mu_{1} \cdot Q_{\mathrm{ZC} 1}{ }^{*}(s)-\mu_{\mathrm{M} 1} \cdot Q_{\mathrm{ZM} 1}{ }^{*}(s)=1 \\
& \left(s+\mu_{\mathrm{W} 1}+\lambda_{\mathrm{W} 11}+\lambda_{\mathrm{L} 1}\right) \cdot Q_{\mathrm{ZW} 1}{ }^{*}(s)-\mu_{\mathrm{W} 11} \cdot Q_{\mathrm{B}}{ }^{*}(s) \\
& \quad-\lambda_{\mathrm{W} 1} \cdot R_{0}{ }^{*}(s)-\mu_{\mathrm{L} 1} \cdot Q_{\mathrm{ZW} 2}{ }^{*}(s)=0 \\
& \left(s+\mu_{\mathrm{W} 2}+\lambda_{\mathrm{W} 22}+\mu_{\mathrm{L} 1}+\lambda_{\mathrm{L} 2}\right) \cdot Q_{\mathrm{ZW} 2}{ }^{*}(s)-\mu_{\mathrm{W} 22} \cdot Q_{\mathrm{B}}{ }^{*}(s) \\
& \quad-\lambda_{\mathrm{W} 2} \cdot R_{0}{ }^{*}(s)-\mu_{\mathrm{L} 2} \cdot Q_{\mathrm{ZW} 3}{ }^{*}(s)-\lambda_{\mathrm{L} 1} \cdot Q_{\mathrm{ZW} 1}{ }^{*}(s)=0 \\
& \left(s+\mu_{\mathrm{W} 3}+\lambda_{\mathrm{W} 33}+\mu_{\mathrm{L} 2}\right) \cdot Q_{\mathrm{ZW} 33}{ }^{*}(s)-\mu_{\mathrm{W} 33} \cdot Q_{\mathrm{B}}{ }^{*}(s) \\
& \quad-\lambda_{\mathrm{W} 3} \cdot R_{0}{ }^{*}(s)-\lambda_{\mathrm{L} 2} \cdot Q_{\mathrm{ZW} 2}{ }^{*}(s)=0 \\
& \left(s+\mu_{1}+\lambda_{2}\right) \cdot Q_{\mathrm{ZC} 1}{ }^{*}(s)-\mu_{2} \cdot Q_{\mathrm{ZC} 2}{ }^{*}(s)-\lambda_{1} \cdot R_{0}{ }^{*}(s)=0 \\
& \left(s+\mu_{2}+\lambda_{3 \mathrm{R}}\right) \cdot Q_{\mathrm{ZC} 2}{ }^{*}(s)-\mu_{3 \mathrm{R}} \cdot Q_{\mathrm{ZR} 1}{ }^{*}(s)-\lambda_{2} \cdot Q_{\mathrm{ZC} 1}{ }^{*}(s)=0 \\
& \left(s+\mu_{3 \mathrm{R}}+\lambda_{3}\right) \cdot Q_{\mathrm{ZR} 1}{ }^{*}(s)-\mu_{3} \cdot Q_{\mathrm{ZC} 3}{ }^{*}(s)-\lambda_{3 \mathrm{R}} \cdot Q_{\mathrm{ZC} 2}{ }^{*}(s)=0 \\
& \left(s+\mu_{3}+\lambda_{4}\right) \cdot Q_{\mathrm{ZC} 3}{ }^{*}(s)-\mu_{4} \cdot Q_{\mathrm{ZC} 4}{ }^{*}(s)-\lambda_{3} \cdot Q_{\mathrm{ZR} 1}{ }^{*}(s)=0 \\
& \left(s+\mu_{4}+\lambda_{5 \mathrm{R}}\right) \cdot Q_{\mathrm{ZC} 4}{ }^{*}(s)-\mu_{5 \mathrm{R}} \cdot Q_{\mathrm{ZR} 2}{ }^{*}(s)-\lambda_{4} \cdot Q_{\mathrm{ZC} 3}{ }^{*}(s)=0
\end{aligned}
$$




$$
\begin{aligned}
& \left(s+\mu_{5 \mathrm{R}}+\lambda_{6}\right) \cdot \mathrm{Q}_{\mathrm{ZR} 2}{ }^{*}(s)-\mu_{6} \cdot Q_{\mathrm{ZC} 5}{ }^{*}(s)-\lambda_{5 \mathrm{R}} \cdot Q_{\mathrm{ZC} 4}{ }^{*}(s)=0 \\
& \left(s+\mu_{6}+\lambda_{7}\right) \cdot Q_{\mathrm{ZC} 5}{ }^{*}(s)-\mu_{7} \cdot Q_{\mathrm{ZC} 6}{ }^{*}(s)-\lambda_{6} \cdot Q_{\mathrm{ZR} 2}{ }^{*}(s)=0 \\
& \left(s+\mu_{7}+\lambda_{8}\right) \cdot Q_{\mathrm{ZC} 6}{ }^{*}(s)-\mu_{8} \cdot Q_{\mathrm{B}}{ }^{*}(s)-\lambda_{7} \cdot Q_{\mathrm{ZC} 5}{ }^{*}(s)=0 \\
& \left(s+\mu_{\mathrm{M} 1}+\lambda_{\mathrm{M} 2}\right) \cdot Q_{\mathrm{ZM} 1}{ }^{*}(s)-\mu_{\mathrm{M} 2} \cdot Q_{\mathrm{ZK} 1}{ }^{*}(s)-\lambda_{\mathrm{M} 1} \cdot R_{0}{ }^{*}(s)=0 \\
& \left(s+\mu_{\mathrm{M} 2}+\lambda_{\mathrm{M} 3}\right) \cdot Q_{\mathrm{ZK} 1}{ }^{*}(s)-\mu_{\mathrm{M} 3} \cdot Q_{\mathrm{ZM} 2}{ }^{*}(s)-\lambda_{\mathrm{M} 2} \cdot Q_{\mathrm{ZM} 1}{ }^{*}(s)=0 \\
& \left(s+\mu_{\mathrm{M} 3}+\lambda_{\mathrm{M} 4}\right) \cdot Q_{\mathrm{ZM} 2}{ }^{*}(s)-\mu_{\mathrm{M} 4} \cdot Q_{\mathrm{ZM} 3}{ }^{*}(s)-\lambda_{\mathrm{M} 3} \cdot Q_{\mathrm{ZK}}{ }^{*}(s)=0 \\
& \left(s+\mu_{\mathrm{M} 4}+\lambda_{\mathrm{M} 5}\right) \cdot Q_{\mathrm{ZM} 3}{ }^{*}(s)-\mu_{\mathrm{M} 5} \cdot Q_{\mathrm{ZM} 4}{ }^{*}(s)-\lambda_{\mathrm{M} 4} \cdot Q_{\mathrm{ZM} 2}{ }^{*}(s)=0 \\
& \left(s+\mu_{\mathrm{M} 5}+\lambda_{\mathrm{M} 6}\right) \cdot \mathrm{Q}_{\mathrm{ZM} 4}{ }^{*}(s)-\mu_{\mathrm{M} 6} \cdot \mathrm{Q}_{\mathrm{ZK} 2}{ }^{*}(s)-\lambda_{\mathrm{M} 5} \cdot Q_{\mathrm{ZM} 3}{ }^{*}(s)=0 \\
& \left(s+\mu_{\mathrm{M} 6}+\lambda_{\mathrm{M} 7}\right) \cdot Q_{\mathrm{ZK} 2}{ }^{*}(s)-\mu_{\mathrm{M} 7} \cdot Q_{\mathrm{ZM} 5}{ }^{*}(s)-\lambda_{\mathrm{M} 6} \cdot Q_{\mathrm{ZM} 4}{ }^{*}(s)=0 \\
& \left(s+\mu_{\mathrm{M} 7}+\lambda_{\mathrm{M} 8}\right) \cdot Q_{\mathrm{ZM} 5}{ }^{*}(s)-\mu_{\mathrm{M} 8} \cdot Q_{\mathrm{U}}{ }^{*}(s)-\lambda_{\mathrm{M} 7} \cdot Q_{\mathrm{ZK} 2}{ }^{*}(s)=0 \\
& \left(s+\mu_{\mathrm{M} 8}+\lambda_{\mathrm{M} 9}\right) \cdot Q_{\mathrm{U}}{ }^{*}(s)-\mu_{\mathrm{M} 9} \cdot Q_{\mathrm{B}}{ }^{*}(s)-\lambda_{\mathrm{M} 8} \cdot Q_{\mathrm{ZM} 5}{ }^{*}(s)=0 \\
& \left(s+\mu_{\mathrm{W} 11}+\mu_{\mathrm{W} 22}+\mu_{\mathrm{W} 33}+\mu_{8}+\mu_{\mathrm{CSP}}+\mu_{\mathrm{M} 9}\right) \cdot Q_{\mathrm{B}}{ }^{*}(s) \\
& -\lambda_{\mathrm{CSP}} \cdot R_{0}{ }^{*}(s)-\lambda_{\mathrm{W} 11} \cdot Q_{\mathrm{ZW} 1}{ }^{*}(s)-\lambda_{\mathrm{W} 22} \cdot Q_{\mathrm{ZW} 2}{ }^{*}(s) \\
& -\lambda_{\mathrm{W} 33} \cdot Q_{\mathrm{ZW} 3}{ }^{*}(s)-\lambda_{8} \cdot Q_{\mathrm{ZC} 6}{ }^{*}(s)-\lambda_{\mathrm{M} 9} \cdot Q_{\mathrm{U}}{ }^{*}(s)=0
\end{aligned}
$$

The achieved dependents (3) enable calculation of probability values (symbolically) of the analysed FAS staying in particular states.

\section{Operational statistics (repair, damage) of representative FAS}

The analysis of FAS operation process was conducted for $n=20$ diverse systems. The structure of the examined fire alarm systems correspond to representative devices employed in fire protection of transport facilities. Operational research (renewal, damage) was conducted for the following FAS (Figure 5):

- FAS with an addressable fire alarm control unit (FACU) and one detection loop ( $n=15$ units);

- FAS with an addressable fire alarm control unit and two detection loops ( $n=3$ units);

- FAS with an addressable FACU, three detection loops, one control-monitoring loop for monitoring fixed extinguishing devices and generating their tripping signal ( $n=2$ units).

All of the aforementioned FAS were operated in similar environmental conditions (temperature, humidity, pressure, etc.) in transport buildings. Owing to the importance of FAS in ensuring the transport process safety, the service team dealing with repairs and restorations was available within 2 hours from the damage being reported by persons supervising the operation (for $n=15$ FAS). Other systems $(n=5)$ had the damage report response time extended to 4 hours due to the detection over transport facilities buildings, which do not pose a direct threat for the passenger transport (e.g. warehouses, sheds, etc.).

The $n=20$ examined FAS included all devices, which are employed in fire protection of transport facilities (e.g. detectors, manual call points, input / output modules, adapters, fire alarm central unit, etc.). In order to elaborate FAS operational statistics all occurring damages and repairs were assigned to individual groups of respective devices (Figures 6 and 7). Individual groups of devices compile a whole fire alarm system with different functional structures executing the process of fire detection.

Detectors, which in the operational process are responsible for fire detection, are ranked as the most important group of devises. During the research this group of devices consisted of detectors from three main producers. Technical parameters (e.g. charging, working temperature, acceptable supply voltage fluctuations, etc.) of these detectors from these producers are identical. To calculate operational parameters a maximum repair (restoration) and damage time was adopted from given $n=20$ FAS.

Tests on the FAS operational process covered systems with various technical structures: focused (all lines or detection loops connected to a single fire alarm control panel), dispersed - up to four CSPs connected in a network, and mixed, i.e. a combination of the above-mentioned structures. FAS operated in various environments and atmospheric conditions: internal (utility and industrial rooms used by officials, railway

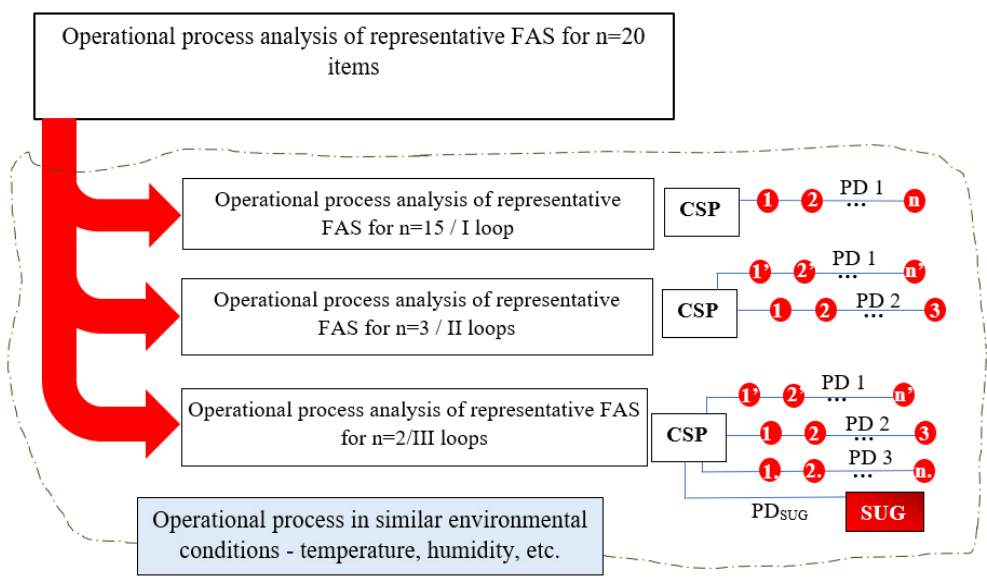

Fig. 5 Types of analysed FAS [own elaboration] 


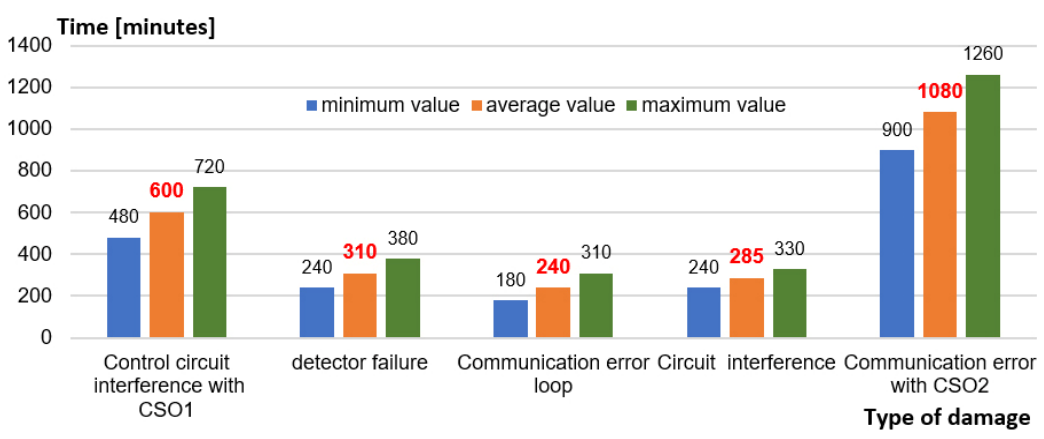

Fig. 6 The minimum, average and maximum value of the repair time of individual FAS components and devices installed on detection loops Nos. 1, 2, 3 and the control loop for a concentrated system [own elaboration]

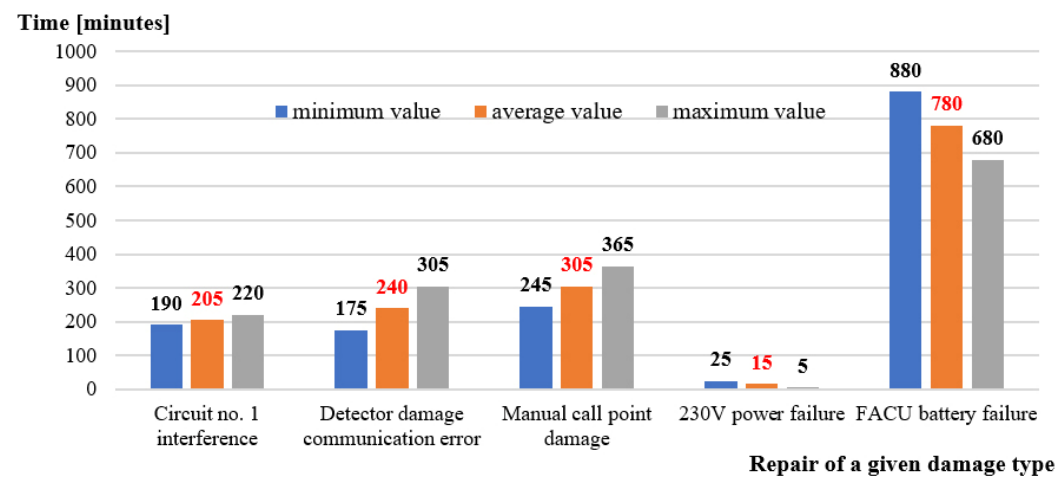

Fig. 7 Types of repairs with the indication of the minimum, average and maximum value of the repair time of individual elements and FAS devices on an annual basis, installed on detection loops Nos. 1, 2, 3 and the control loop [own elaboration]

signal towers, cash desks, built-up area of the main station), external (FAS elements located on the detection lines and loops of waiting rooms, platforms, underground passages, etc.). The ranges of changes in environmental parameters temperature, pressure and humidity during operational tests - changed - especially the temperature (range of changes from $-15^{\circ} \mathrm{C}$ to $+27^{\circ} \mathrm{C}$ ). Detectors, acoustic-optical signaling devices and FAS control modules were the most exposed to condition changes of the operational process. All elements of the FAS that were responsible for fire protection of the facilities were subjected to operational tests. The research was carried out for FAS elements of the following companies: Bosch, Schrack and Polon-Alfa. They are most often installed and used on the Polish market. FAS with local service and service available at the time of failure were tested - the maximum time for intervention is 4 hours. This resulted in a change in the times of the FAS renewal process. The determination of the failure intensity $\lambda$ of individual FAS elements was carried out by grouping the given types of linear elements - e.g. detectors in a specific period of operational time to the total number of these elements in the system.

Adopting maximum repair time for $n=20$ examined FAS results from reaction time of the operator supervising operational process, technical abilities of the service team (replacement devices availability in storage), damage location, replacement duration of e.g. detector. Adopting maximum repair time for FAS results in the system being at that time in a state of unfitness or partial unfitness (e.g. by shutting off the detection line where the damage occurred). The aim of FAS is to shorten the repair time by applying various technical solutions (e.g. redundancy) so the repair process is executed while the whole system is working.

All FAS were equipped with a synoptic panel, which display places where the damage occurs (control area or room number) to the operators supervising the operational process.

Some FAS solutions $(n=4)$ employed additional remote detector activation indicators, which are fitted in corridors outside room entrance. Activation of indicator fitted above the doorway (red LED matrix in a white case) enables determining from long distance in which room fire broke out or a detector is unfit.

For $n=4$ FAS the following technical and fire protection installations were fitted:

- gravity smoke vent systems in staircases;

- access control system;

- fire dampers in the household mechanical ventilation system;

- ventilation central units and fans in a household mechanical ventilation system;

- gas valve. 
Calculating repair time and fire alarm system unfitness

The maximum repair time for a given type of FAS $(n=20$ units):

$T_{\operatorname{maxl}}=5.5[\mathrm{~h}]$ for the group of detection loop damage;

$T_{\max 2}=7.66[\mathrm{~h}]$ for the group of detector damage;

$T_{\max 3}=5.08[\mathrm{~h}]$ for the group of manual call point damage (MCP);

$T_{\max 1}=13.16[\mathrm{~h}]$ for the group of power supply failure.

For given different types of damage the repair time (restoration) coefficient respectively amounts to:

$\mu_{1}=1 / 5.5=0.1818\left[\mathrm{~h}^{-1}\right]$ for the detection loop damage;

$\mu_{2}=1 / 7.66=0.1305\left[\mathrm{~h}^{-1}\right]$ for detector damage;

$\mu_{3}=1 / 5.08=0.1968\left[\mathrm{~h}^{-1}\right]$ for the manual call point damage

(MCP);

$\mu_{4}=1 / 13.16=0.0759\left[h^{-1}\right]$ for the power supply failure.

Figure 8 shows chosen FAS damages, which occur most frequently for $n=20$ of examined systems. The damages are grouped according to symptoms, which are displayed on the FAS diagnostic panel.

The maximum FAS unfitness time for different types of damages:

$T_{\operatorname{maxn1}}=19.38[\mathrm{~h}]$ for the group of detection loop damage;

$T_{\operatorname{maxn} 2}=34.42[\mathrm{~h}]$ for the group of detector damage;

$T_{\max n 3}=9.08[\mathrm{~h}]$ for the group of manual call point (MCP) damage;

$T_{\max n 4}=13.42[\mathrm{~h}]$ for the group of power supply failure.

Assuming that:

$K_{\mathrm{g}}=\frac{T_{\mathrm{U}}}{T_{\mathrm{U}}+T_{\mathrm{N}}}$

where: $K_{\mathrm{g}}$ : FAS availability coefficient; $T_{\mathrm{U}}$ : operational time of 1 year $(8760 \mathrm{~h})$, i.e. total time while the facility is available and its usage might be required; $T_{\mathrm{N}}$ : total damages of one type, annualized, i.e. total time while the facility is unavailable, although its usage might be required.

Employing Eq. (4) for the determined unfitness times of examined FAS the following calculations may be exhibited:

$\frac{T_{\mathrm{U}}}{T_{\mathrm{U}}+T_{\mathrm{N}}}=\frac{8760-19.38}{8760}=\frac{8740.62}{8760}=0.997787=K_{\mathrm{g} 1}$

for the group of detection loop damage;

$\frac{T_{\mathrm{U}}}{T_{\mathrm{U}}+T_{\mathrm{N}}}=\frac{8760-34.42}{8760}=\frac{8725.58}{8760}=0.996070=K_{\mathrm{g} 2}$

for the group of detector damage;

$\frac{T_{\mathrm{U}}}{T_{\mathrm{U}}+T_{\mathrm{N}}}=\frac{8760-9.08}{8760}=\frac{8750.92}{8760}=0.998963=K_{\mathrm{g} 3}$

for the group of manual call point (MCP) damage;

$\frac{T_{\mathrm{U}}}{T_{\mathrm{U}}+T_{\mathrm{N}}}=\frac{8760-13.42}{8760}=\frac{8746.58}{8760}=0.998468=K_{\mathrm{g} 4}$

for the group of power supply failure.

Assuming that $K_{\mathrm{g}}=R_{\mathrm{ZB}}(t)$, then if we know the reliability value $R_{\mathrm{ZB}}(t)$, we can evaluate the intensity of transmission from the state of full fitness to the state of safety hazard. Adopting for the fitness time, the easiest exponential model of distribution, we can employ dependency (5):

$R_{\mathrm{ZB} 1}(t)=\mathrm{e}^{-\lambda_{\mathrm{ZB}} t}$ for $t \geq 0$

so:

$\lambda_{\mathrm{ZB} 1}=-\frac{\ln R_{\mathrm{ZB} 1}(t)}{t}$

For $t=8760[\mathrm{~h}]$ and $R_{\mathrm{ZB} 1}(t)=0.997787$

we obtain:

$\lambda_{\mathrm{ZB} 1}=-\frac{\ln R_{\mathrm{ZB} 1}(t)}{t}=-\frac{\ln 0.997787}{8760}=2.529055 \cdot 10^{-7}\left[\mathrm{~h}^{-1}\right]$

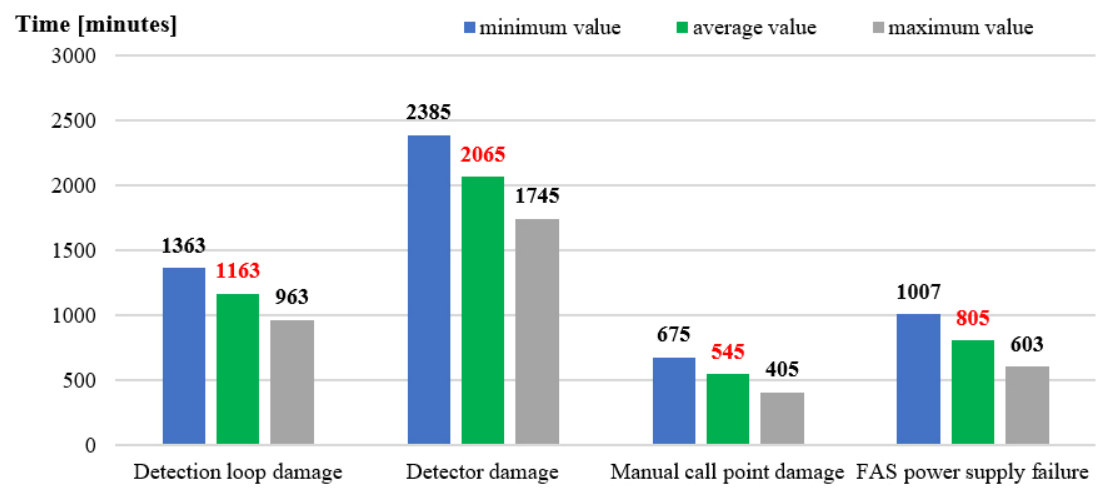

Total FAS unfitness time, annualized

Fig. 8 The total time of failure for the minimum, average and maximum FAS value on an annual basis for individual elements and devices installed on the detection loops Nos. 1, 2, 3 and the control loop [own elaboration] 
For $t=8760[\mathrm{~h}]$ and $R_{\mathrm{ZB} 2}(t)=0.996070$

we obtain:

$$
\lambda_{\mathrm{ZB} 2}=-\frac{\ln R_{\mathrm{ZB} 2}(t)}{t}=-\frac{\ln 0.996070}{8760}=4.495140 \cdot 10^{-7}\left[\mathrm{~h}^{-1}\right]
$$

For $t=8760[\mathrm{~h}]$ and $R_{\mathrm{ZB} 3}(t)=0.998963$

we obtain:

$$
\lambda_{\mathrm{ZB} 3}=-\frac{\ln R_{\mathrm{ZB} 3}(t)}{t}=-\frac{\ln 0.998963}{8760}=1.184404 \cdot 10^{-7}\left[\mathrm{~h}^{-1}\right]
$$

For $t=8760[\mathrm{~h}]$ and $R_{\mathrm{ZB} 4}(t)=0.998468$ we obtain:

$$
\lambda_{\mathrm{ZB} 4}=-\frac{\ln R_{\mathrm{ZB} 4}(t)}{t}=-\frac{\ln 0.998468}{8760}=1.750199 \cdot 10^{-7}\left[\mathrm{~h}^{-1}\right]
$$

Equations (7)-(10) and the calculated intensivities correspond with the given groups of damage characteristics, which are displayed as announcements on FAS diagnostic panel.

There is an operational problem in FAS related to fire sensors - i.e. their susceptibility to detecting phenomena that are not related to fire. About $80 \%$ of fire alarms generated by conventional detectors (single-sensor detectors), unfortunately, result only from processes that simulate the fire phenomenon. This is a significant operational problem for FASs that are connected to the alarm transmission device and fault warning signal is fed to alarm receiving centers (ARC). The likelihood of a false alarm $\left(P_{\mathrm{FA}}\right)$ in FAS is an undesirable phenomenon and various technical and organizational solutions are used to minimize the value of this coefficient - e.g. multi-sensor detectors. The false alarm reported to the fire alarm control panel in the operational tests was not included in the calculations of the operational process coefficients.

\section{Calculations of FAS model with detection and control loops and alarm devices lines}

BlockSim software (Reliasoft BlockSim software) was used to calculate (Grabski 2015; Caban and Walkowiak 2019) availability and reliability of a system staying in respective states for FAS presented model according to the established operational time $8760 \mathrm{~h}$ and the adopted values of repair time (restoration) coefficient and values of reliability determined in the previous sections of this article.

All zonal (partial) availability coefficients exhibited in

\begin{tabular}{|c|c|c|c|c|c|}
\hline \multicolumn{6}{|c|}{ Results for time $t=8760[\mathrm{~h}]$} \\
\hline Name of state & Initial probability & Average probability & Availability for time $t$ & Reliability for time $t$ & Time spent in the state \\
\hline$S_{-} 0$ & 1 & 0.999989866 & 0.99998985 & 0.990461753 & 8759.911222 \\
\hline $\mathrm{S}_{\mathrm{ZZC1}}$ & 0 & $3.68795 \mathrm{E}-06$ & $3.69263 \mathrm{E}-06$ & 0.003918933 & 0.032306436 \\
\hline $\mathrm{S}_{-Z \mathrm{ZC} 2}$ & 0 & $2.46582 \mathrm{E}-07$ & $2.48123 \mathrm{E}-07$ & 0 & 0.002160059 \\
\hline$S_{-Z R 1}$ & 0 & $2.46787 \mathrm{E}-07$ & $2.48111 \mathrm{E}-07$ & 0 & 0.002161856 \\
\hline $\mathrm{S}_{\text {ZZC3 }}$ & 0 & $2.47004 \mathrm{E}-07$ & $2.48111 \mathrm{E}-07$ & 0 & 0.002163757 \\
\hline $\mathrm{S}_{-Z C 4}$ & 0 & $2.47221 \mathrm{E}-07$ & $2.48111 \mathrm{E}-07$ & 0 & 0.002165659 \\
\hline $\mathrm{S}_{-Z R 2}$ & 0 & $2.47438 \mathrm{E}-07$ & $2.48111 \mathrm{E}-07$ & 0 & 0.00216756 \\
\hline $\mathrm{S}_{-Z C 5}$ & 0 & $2.47655 \mathrm{E}-07$ & $2.48111 \mathrm{E}-07$ & 0 & 0.002169461 \\
\hline S_zC6 & 0 & $2.47872 \mathrm{E}-07$ & $2.48111 \mathrm{E}-07$ & 0 & 0.002171362 \\
\hline$S_{-Z W 1}$ & 0 & $1.53927 \mathrm{E}-06$ & $1.54059 \mathrm{E}-06$ & 0.001032582 & 0.013484024 \\
\hline $\mathrm{S}_{-Z W 2}$ & 0 & $7.69856 \mathrm{E}-07$ & $7.70296 \mathrm{E}-07$ & 0.001032582 & 0.006743938 \\
\hline S_zW3 & 0 & $7.69856 \mathrm{E}-07$ & $7.70296 \mathrm{E}-07$ & 0.001032582 & 0.006743938 \\
\hline$S_{\_} B$ & 0 & $1.78082 \mathrm{E}-07$ & $1.78099 \mathrm{E}-07$ & 0.001525851 & 0.00156 \\
\hline $\mathrm{S}_{-} \mathrm{ZM1}$ & 0 & $6.81537 \mathrm{E}-07$ & $6.82366 \mathrm{E}-07$ & 0.000995718 & 0.005970267 \\
\hline $\mathrm{S}_{-Z K 1}$ & 0 & $1.10858 \mathrm{E}-07$ & $1.11312 \mathrm{E}-07$ & 0 & 0.000971116 \\
\hline $\mathrm{S}_{-} \mathrm{ZM} 2$ & 0 & $1.10921 \mathrm{E}-07$ & $1.11312 \mathrm{E}-07$ & 0 & 0.00097167 \\
\hline $\mathrm{S}_{-} \mathrm{ZM} 3$ & 0 & $1.10985 \mathrm{E}-07$ & $1.11312 \mathrm{E}-07$ & 0 & 0.000972226 \\
\hline $\mathrm{S}_{-} \mathrm{ZM} 4$ & 0 & $1.11048 \mathrm{E}-07$ & $1.11312 \mathrm{E}-07$ & 0 & 0.000972783 \\
\hline $\mathrm{S}_{\text {ZZMK} 2}$ & 0 & $1.11112 \mathrm{E}-07$ & $1.11312 \mathrm{E}-07$ & 0 & 0.000973339 \\
\hline $\mathrm{S}_{-Z M 5}$ & 0 & $1.11175 \mathrm{E}-07$ & $1.11312 \mathrm{E}-07$ & 0 & 0.000973896 \\
\hline$S_{-} U$ & 0 & $1.11239 \mathrm{E}-07$ & $1.11312 \mathrm{E}-07$ & 0 & 0.000974452 \\
\hline
\end{tabular}
Tables 1 and 2 in the subsequent FAS operational process

Table 1 Calculated values of reliability coefficients for the respective FAS states (Figure 4) 
Table 2 Calculations of FAS availability and reliability coefficient values for state $S_{-} 0$

\begin{tabular}{|c|c|c|c|}
\hline Calculated step & Time $[\mathrm{h}]$ & Availability $(t)$ & Reliability $(t)$ \\
\hline 0 & 0 & 0 & 0 \\
\hline 1 & 1.25 & 0.999998738 & 0.999998632 \\
\hline 2 & 2.25 & 0.999997868 & 0.999997538 \\
\hline 3 & 3.25 & 0.999997106 & 0.999996444 \\
\hline 4 & 4.25 & 0.999996437 & 0.99999535 \\
\hline 5 & 5.25 & 0.999995851 & 0.999994256 \\
\hline 6 & 6.25 & 0.999995337 & 0.999993162 \\
\hline 7 & 7.25 & 0.999994885 & 0.999992068 \\
\hline 8 & 8.25 & 0.999994488 & 0.999990974 \\
\hline 9 & 9.25 & 0.999994137 & 0.99998988 \\
\hline 10 & 10.25 & 0.999993826 & 0.999988786 \\
\hline 11 & 11.25 & 0.999993551 & 0.999987692 \\
\hline$\ldots$ & $\ldots$ & $\ldots$ & $\ldots$ \\
\hline 8748 & 8748.25 & 0.99998985 & 0.990474485 \\
\hline 8749 & 8749.25 & 0.99998985 & 0.990473402 \\
\hline 8750 & 8750.25 & 0.999989885 & 0.990472318 \\
\hline 8751 & 8751.25 & 0.99998985 & 0.990471234 \\
\hline 8752 & 8752.25 & 0.99998985 & 0.990470151 \\
\hline 8753 & 8753.25 & 0.99998985 & 0.990469067 \\
\hline 8754 & 8754.25 & 0.99998985 & 0.990467984 \\
\hline 8755 & 8755.25 & 0.99998985 & 0.9904669 \\
\hline 8756 & 8756.25 & 0.99998985 & 0.990465816 \\
\hline 8757 & 8757.25 & 0.99998985 & 0.990464733 \\
\hline 8758 & 8758.25 & 0.99998985 & 0.990463649 \\
\hline 8759 & 8759.25 & 0.99998985 & 0.990462565 \\
\hline 8760 & 8760 & 0.99998985 & 0.990461753 \\
\hline
\end{tabular}

stabilise their values and remain fixed and at a low level. The probability of a fire alarm system staying in $R(t)$ state is very low for individual states of hazard and safety unreliability

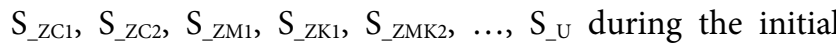
operational period - Figures 9 and 10 .

In FAS, apart from the issue of the shortest possible threat detection time by sensors (which are located on loops or detection lines), a very important matter is also the reliability and probability of the so-called false alarms. FAS is used in adverse conditions where, in addition to temperature, humidity, and pressure changes or the occurrence of dust in the environment of a given room, the devices are also susceptible to the effects of external and internal electromagnetic disturbances. Therefore, a very important issue already during the design phase is to determine the exploitation reliability in various environmental conditions - favourable or unfavourable to the operation process. At this stage we define the so-called the minimum operating path for a specific FAS structure proposed in a given technical solution. The minimum operating path for FAS specifies the minimum set of elements for the facility - e.g. detectors, modules or smoke exhaust dampers, the fitness of which ensures the facility fitness - in this case, the system. Since all elements included in the minimum path, e.g. fire alarm control panel, detection loop or detectors, must be fit to ensure FAS fitness, the minimum operating path is a reliable serial structure. In case of such a reliability structure, the damage to a single element on the so-called operating path makes the entire system unfit. Then FAS reliability depends on the "weakest link" present in this system, which is characterized by the failure intensity $\lambda$ of individual elements in the operating path. The failure intensity of FAS components is understood as the number of failures of this facility per time unit. In the literature, the failure intensity function is sometimes called lambda - a risk characteristic or function. Therefore, a very important issue when considering the FAS reliability is to determine accurately the value of failure intensity $\lambda$ of individual components of the system. With the serial reliability structure, the resultant FAS operating fitness is determined by the 


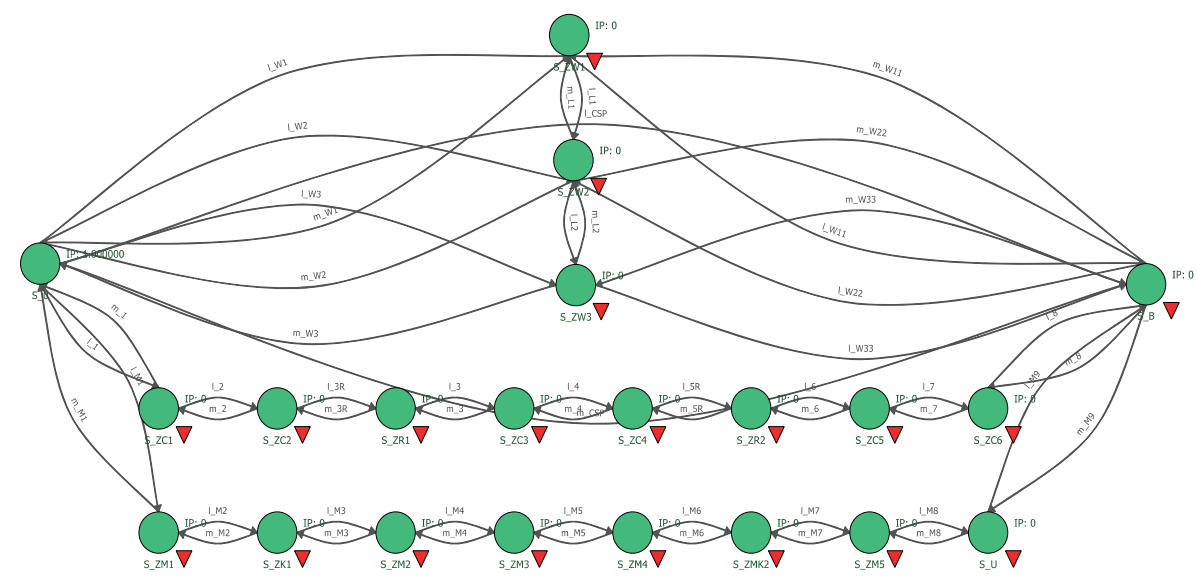

Fig. 9 Migration of possible FAS states - FAS model with detection and control loops and alarm devices lines (Fig. 2) [own elaboration using BlockSim software]

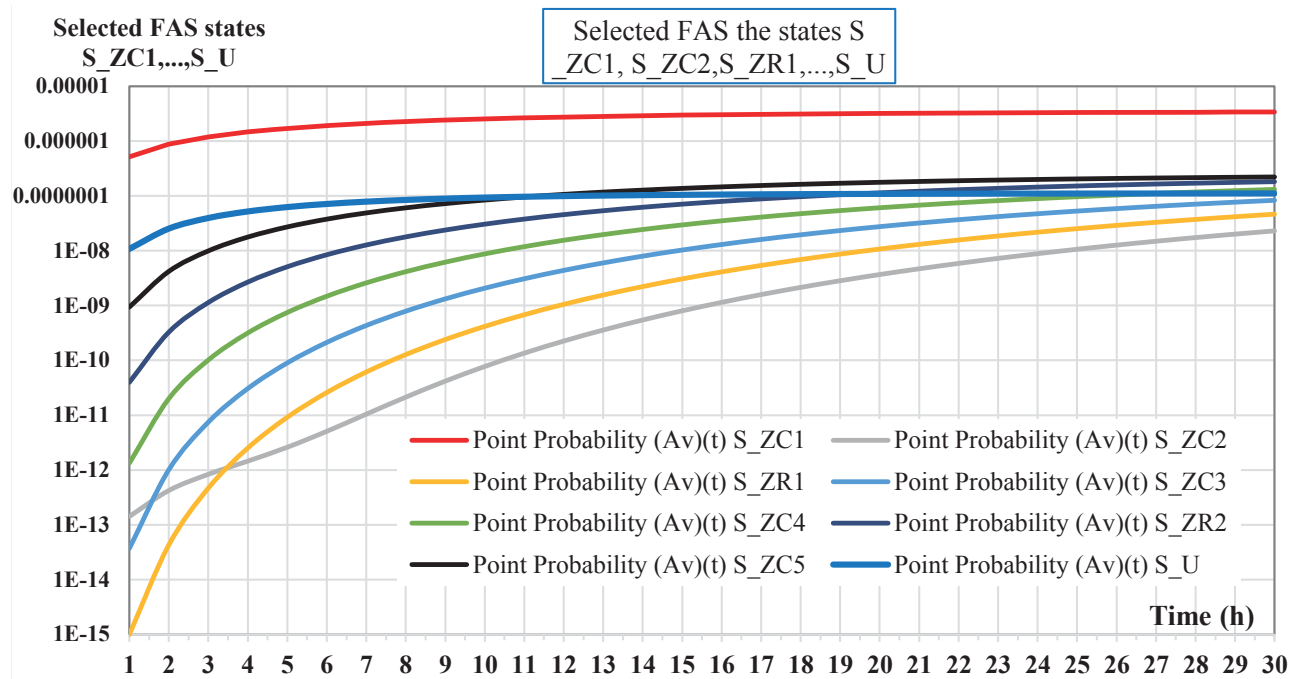

Fig. 10 The value of the probability of staying in selected states of individual safety hazard states and state of safety unreliability $S_{z} z \mathrm{C} 1$, $\mathrm{S}_{-} \mathrm{ZR1}, \mathrm{S}_{-} \mathrm{ZC} 4, \mathrm{~S}_{-} \mathrm{ZC} 5, \mathrm{~S}_{z} \mathrm{ZC2}, \mathrm{S}_{-} \mathrm{ZC} 3, \mathrm{~S}_{-} \mathrm{ZR} 2, \mathrm{~S}_{-} \mathrm{U}$ in the initial period of using the fire alarm system (system lifetime $\Delta t=29$ hours) [own elaboration]

lowest value of the failure intensity $\lambda$ of the element which occurs in this operating path, $R(t)_{\mathrm{FAS}}=R_{1}(t) \cdot R_{2}(t) \ldots \cdot R_{n}(t)$, where: $R(t)_{\mathrm{FAS}}$ - FAS reliability, $R_{1}(t)$ - control panel reliability, $R_{2}(t)$ - detection line reliability, $\ldots, R_{n}(t)$ - power supply reliability. The individual failure intensities $\lambda$ of FAS elements were determined through experimental tests on real systems. Figure 10 shows the process of establishing the individual FAS safety states at the initial operating time. In general, the FAS operation process can be divided into three areas: I. initial phase, the so-called "infancy period", II. period of normal operating after the so-called "running in" and III. decommissioning the system as a result of an increase in failure intensity $\lambda$. FAS in buildings practically does not "survive" till the third period. It is replaced earlier for several reasons: the so-called moral ageing of elements, but also the advancements of electronics, signal analysis techniques, and of sensors detecting fire phenomenon. Therefore, the most important FAS operational issue is the first phase after putting the system into operation, where damages related to the so-called startup process frequently occur. The dominant safety state which determines the failure in this time span is the $S_{\text {zCl }}$ state of safety hazard. This state occurs in the detection loop No. 1 - Figure 2 - FAS diagram, Figure 4 - transition graph. The value of the probability of the transition between states, i.e., failure occurrence in the FAS is the highest and amounts to $5.18456 \mathrm{E}-07$ compared to e.g. the state $S_{-}=2.53168 \mathrm{E}-08$ (Figure 10). After the initial operating period of $\Delta t=30$ hours, and the occurrence of the first phase so-called "infant diseases" follows the process of establishing the probabilities of transitions between states in FAS. The individual values of the probability of transitions stabilize after this time. They reach a maximum value of 4.64146E-08. After $\Delta t=30$ hours, all the probabilities of transitions between the safety states are equivalent, and 
differ only slightly - which means that in FAS there is no so-called dominant state.

\section{Conclusion}

Fire alarm systems which supervise the fire safety of individual buildings and so called vast transport areas (e.g. airports, logistics base, railway stations) have various reliability and functional structures. Employing different connection structures inside these systems (focused, dispersed and mixed) is the function of the performed operational tasks and the devised scenario - fire algorithm for the supervised buildings. Complex FAS have half a dozen to several dozen of detection loops, as well as acoustic-optical signalling buses, fire protection input/output modules, e.g. smoke vent or fixed gas extinguishing devices. Because of safety extent and the executed operational tasks and fire controls, the reliability and operational structure of such systems is mixed. All available on the market technical measures and functional solutions are applied in order to increase FAS reliability. The article presents an authorial model and an operational and reliability analysis of a fire alarm system, which is operated within a transport building. A focused fire alarm system was used to depict safety relationships occurring in this technical facility where an addressable FACU with detection and detection loops was connected with alarm devices lines - Figure 4. In order to determine operational and reliability parameters of the chosen technical facilities research and analysis were conducted of results for $n=20$ representative FAS, which were used in similar environmental conditions. The average value of the probability of a system staying in the state of fitness was $S_{-0}=0.999989866$, whereas the time spent in this state was 8759.9 [h]. The computer simulation for the chosen fire alarm system was run within the time $t=1$ year of safety system operation. When considering the so-called zonal (partial) availability coefficients for FAS states of $\mathrm{S}_{-Z C 1}, \mathrm{~S}_{-\mathrm{ZC} 2}, \ldots, \mathrm{S}_{-} \mathrm{U}$ displayed in Table 1 it can be observed, that the $\mathrm{S}_{\mathrm{ZC} 1}$ state is dominant at the initial operational stage. Therefore, when designing FAS, particular attention to the transition between the states of fitness $S_{-} 0$ and the state of safety hazard S_zC1 should be paid.

In the subsequent study of FAS the authors plan to devise reliability-operational models for FAS in dispersed structure. This will enable the analysis of systems, which are designed to serve several fire alarm central units.

Open Access: This article is licensed under a Creative Commons Attribution 4.0 International License, which permits use, sharing, adaptation, distribution and reproduction in any medium or format, as long as you give appropriate credit to the original author(s) and the source, provide a link to the Creative Commons licence, and indicate if changes were made.

The images or other third party material in this article are included in the article's Creative Commons licence, unless indicated otherwise in a credit line to the material. If material is not included in the article's Creative Commons licence and your intended use is not permitted by statutory regulation or exceeds the permitted use, you will need to obtain permission directly from the copyright holder.

To view a copy of this licence, visit http://creativecommons.org/licenses/by/4.0/

\section{References}

Billinton R, Allan RN (1996). Reliability Evaluation of Power Systems. New York: Plenum Press.

Burdzik R, Konieczny Ł, Figlus T (2013). Concept of on-board comfort vibration monitoring system for vehicles. In: Mikulski J (ed), Activities of Transport Telematics. Heidelberg: Springer.

Caban D, Walkowiak T (2019). Dependability analysis of hierarchically composed system-of-systems. In: Proceedings of the 13th International Conference on Dependability and Complex Systems.

Cadena JE, Osorio AF, Torero JL, et al. (2020). Uncertainty-based decision-making in fire safety: Analyzing the alternatives. Journal of Loss Prevention in the Process Industries, 68: 104288.

Ding Q, Peng Z, Liu T, et al. (2014). Building Fire alarm system with multi-sensor and information fusion technology based on D-S evidence theory. In: Proceedings of the International Symposium on Computer, Consumer and Control, Taichung.

Ding L, Ji J, Khan F, Li X, Wan S (2020). Quantitative fire risk assessment of cotton storage and a criticality analysis of risk control strategies. Fire and Materials, 44: 165-179.

Duer S, Zajkowski K, Płocha I, et al. (2013). Training of an artificial neural network in the diagnostic system of a technical object. Neural Computing and Applications, 22: 1581-1590.

Feo-Arenis S, Westphal B, Dietsch D, et al. (2014). The Wireless Fire Alarm System: Ensuring Conformance to Industrial Standards through Formal Verification. In: Jones C, Pihlajasaari P, Sun J (eds), FM 2014: Formal Methods. Cham, Switzerland: Springer.

Fonollosa J, Solórzano A, Marco S (2018). Chemical sensor systems and associated algorithms for fire detection: A review. Sensors, 18: 553.

Forell B, Peschke J, Einarsson S, et al. (2016). Technical reliability of active fire protection features - generic database derived from German nuclear power plants. Reliability Engineering \& System Safety, 145: 277-286.

Ge Z, Xu G, Chua KH, et al. (2017). Computational fluid dynamics studies on the effectiveness of sidewall sprinklers to suppress the fire at the undercarriage of mass rapid transit train. Building Simulation, 10: 563-571.

Grabski F (2015). Semi-Markov Processes: Applications in System Reliability and Maintenance. Amsterdam: Elsevier. 
Gunawaardena AE, Ruwanthika RMM, Jayasekara AGBP (2016). Computer vision based fire alarming system. In: Proceedings of Moratuwa Engineering Research Conference (MERCon), Moratuwa, Sri Lanka.

Idris AM, Rusli R, Burok NA, et al. (2020). Human factors influencing the reliability of fire and gas detection system. Process Safety Progress, 39: e12116.

Jafari MJ, Pouyakian M, Khanteymoori A, et al. (2020). Reliability evaluation of fire alarm systems using dynamic Bayesian networks and fuzzy fault tree analysis. Journal of Loss Prevention in the Process Industries, 67: 104229.

Jee SW, Lee CH, Kim SK, et al. (2014). Development of a traceable fire alarm system based on the conventional fire alarm system. Fire Technology, 50: 805-822.

Jennings M (2020). The oil and gas industry, the competence assessment of Offshore Installation Managers (OIMs) and Control Room Operators (CROs) in emergency response, and the lack of effective assessment of underpinning technical knowledge and understanding. Journal of Loss Prevention in the Process Industries, 65: 104090.

Joglar F (2016). Reliability, availability, and maintainability. In: Hurley M (ed), SFPE Handbook of Fire Protection Engineering. New York: Springer.

Kaniewski P, Smagowski P, Konatowski S (2019). Ballistic target tracking with use of cinetheodolites. International Journal of Aerospace Engineering, 2019: 1-13.

Kierzkowski A, Kisiel T (2015). Airport security screeners reliability analysis. In: Proceedings of the IEEE International Conference on Industrial Engineering and Engineering Management IEEM, Singapore.

Kierzkowski A, Kisiel T (2017). Simulation model of security control system functioning: A case study of the Wroclaw Airport terminal. Journal of Air Transport Management, 64(B): 173-185.

Klimczak T, Paś J (2019). Reliability and operating analysis of transmission of alarm signals of distributed fire signaling system. Journal of KONBiN, 49: 165-174.

Klimczak T, Paś J (2020). Basics of exploitation of fire alarm systems in transport facilities. Warsaw: Military University of Technology. (in Polish)

Kostrzewski M (2018). Analysis of selected acceleration signals measurements obtained during supervised service conditionsStudy of hitherto approach. Journal of Vibroengineering, 20: 1850-1866.

Krzykowski M, Paś J, Rosiński A (2019). Assessment of the level of reliability of power supplies of the objects of critical infrastructure. IOP Conference Series: Earth and Environmental Science, 214: 012018 .

Kukulski J, Jacyna M, Gołębiowski P (2019). Finite element method in assessing strength properties of a railway surface and its elements. Symmetry, 11: 1014.

Łabowski M, Kaniewski P (2015). Motion compensation for unmanned aerial vehicle's synthetic aperture radar. In: Proceedings of Signal Processing Symposium (SPSympo), Debe, Poland.

Laskowski D, Łubkowski P, Pawlak E, et al. (2015). Anthropotechnical systems reliability. In: Nowakowski T, Młyńczak M, Jodejko-
Pietruczuk A, et al. (eds), Safety and Reliability: Methodology and Applications-Proceedings of the European Safety and Reliability Conference ESREL 2014. London: CRC Press/Balkema.

Liu K (2013). An optimization of intelligent fire alarm system for high-rise building based on ANASYS. In: Du Z (ed), Intelligence Computation and Evolutionary Computation. Springer. Berlin: Springer.

Long Z, Yang Y, Liu C, et al. (2021). Study on the optimal operation mode of ventilation system during metro double-island platform fire. Building Simulation, 14: 779-792.

Losurdo F, Dileo I, Siergiejczyk M, et al. (2017). Innovation in the ICT infrastructure as a key factor in enhancing road safety. A multi-sectoral approach. In: Proceedings 25th International Conference on Systems Engineering (ICSEng), Las Vegas, USA.

Mahdipour E, Dadkhah C (2014). Automatic fire detection based on soft computing techniques: review from 2000 to 2010. Artificial Intelligence Review, 42: 895-934.

Mao Q, Li N, Peña-Mora F (2019). Quality function deploymentbased framework for improving the resilience of critical infrastructure systems. International Journal of Critical Infrastructure Protection, 26: 100304.

Mi Z, Zhang W, Wu X, et al. (2020). Sniffer-Net: quantitative evaluation of smoke in the wild based on spatial-temporal motion spectrum. Neural Computing and Applications, 32: 9165-9180.

Naziris IA, Lagaros ND, Papaioannou K (2016). Optimized fire protection of cultural heritage structures based on the analytic hierarchy process. Journal of Building Engineering, 8: 292-304.

Østrem L, Sommer M (2021). Inherent fire safety engineering in complex road tunnels - Learning between industries in safety management. Safety Science, 134: 105062.

Paś J (2016). Shock a disposable time in electronic security systems. Journal of KONBiN, 38: 5-32.

Paś J, Rosiński A, Wiśnios M, et al. (2018). Electronic security systems. Introduction to the laboratory. Warsaw: Military University of Technology. (in Polish)

Paś J, Klimczak T (2019). Selected issues of the reliability and operational assessment of a fire alarm system. Eksploatacja $i$ Niezawodnosc-Maintenance and Reliability, 21: 553-561.

Paś J, Rosiński A, Szulim M, et al. (2020). Modelling the Safety Levels of ICT Equipment Exposed to Strong Electromagnetic Pulses. In: Proceedings of the 14th International Conference on Dependability and Computer Systems.

Ministry of the Interior and Administration of Poland (2010). Regulation of Ministry of the Interior and Administration of Poland (MSWiA) of 7 June 2010 (Journal of Laws of the Republic of Poland No. 109, item 719) concerning fire protection of buildings and other facilities and grounds. (in Polish)

Rosiński A, Paś J, Łukasiak J, et al. (2019). Exploitation of electronic systems in building objects exposed to impact of strong electromagnetic pulses. In: Proceedings of the 29th European Safety and Reliability Conference (ESREL), Singapore.

Sharma A, Singh PK, Kumar Y (2020). An integrated fire detection system using IoT and image processing technique for smart cities. Sustainable Cities and Society, 61: 102332. 
Siergiejczyk M, Krzykowska K (2014). Some issues of data quality analysis of automatic surveillance at the airport. Diagnostyka, 15: 25-29.

Siergiejczyk M, Krzykowska K, Rosiński A (2015). Reliability assessment of integrated airport surface surveillance system. In: Proceedings of the 10th International Conference on Dependability and Complex Systems.

Siergiejczyk M, Paś J, Dudek E (2017). Reliability analysis of aerodrome's electronic security systems taking into account electromagnetic interferences. In: Walls L, Revie M, Bedford T (eds), Risk, Reliability and Safety: Innovating Theory and Practice: Proceedings of ESREL 2016. London: CRC Press/Balkema.

Stawowy M, Perlicki K, Sumiła M (2017). Comparison of uncertainty multilevel models to ensure ITS services. In: Cepin M, Radim B (eds), Safety and Reliability—Theory and Applications: Proceedings of ESREL 2017. London: CRC Press/Balkema.

Stawowy M, Siergiejczyk M (2017). Application and simulations of uncertainty multilevel models to ensure the ITS services. In: Walls L, Revie M, Bedford T (eds), Risk, Reliability and Safety: Innovating Theory and Practice: Proceedings of ESREL 2016. London: CRC Press/Balkema.
Urbancokova H, Valouch J, Adamek M (2015). Testing of an intrusion and hold-up systems for electromagnetic susceptibility-EFT/B. International Journal of Circuits, Systems and Signal Processing, 9: 40-46.

Verma AK, Srividya A, Karanki DR (2017). Reliability and Safety Engineering. London: Springer.

Vijayalakshmi SR, Muruganand S (2017). Smoke detection in video images using background subtraction method for early fire alarm system. In: Proceedings of the 2nd International Conference on Communication and Electronics Systems (ICCES), Coimbatore, India.

Wang J, Yan W, Xu H, et al. (2018). Investigation of the probability of a safe evacuation to succeed in subway fire emergencies based on Bayesian theory. KSCE Journal of Civil Engineering, 22: 877-886.

Wu H, Wu D, Zhao J (2019). An intelligent fire detection approach through cameras based on computer vision methods. Process Safety and Environmental Protection, 127: 245-256.

Xie Y, Peng M (2019). Forest fire forecasting using ensemble learning approaches. Neural Computing and Applications, 31: 4541-4550. 